\title{
Trend detection in river flow indices in Poland
}

\author{
Mikołaj Piniewski $^{1,2}$ (D) Paweł Marcinkowski ${ }^{1} \cdot$ Zbigniew W. Kundzewicz $^{2,3}$
}

Received: 15 November 2017 / Accepted: 1 February 2018/ Published online: 7 February 2018

(C) The Author(s) 2018. This article is an open access publication

\begin{abstract}
The issue of trend detection in long time series of river flow records is of vast theoretical interest and considerable practical relevance. Water management is based on the assumption of stationarity; hence, it is crucial to check whether taking this assumption is justified. The objective of this study is to analyse long-term trends in selected river flow indices in small- and medium-sized catchments with relatively unmodified flow regime (semi-natural catchments) in Poland. The examined indices describe annual and seasonal average conditions as well as annual extreme conditions-low and high flows. The special focus is on the spatial analysis of trends, carried out on a comprehensive, representative data set of flow gauges. The present paper is timely, as no spatially comprehensive studies (i.e. covering the entire Poland or its large parts) on trend detection in time series of river flow have been done in the recent 15 years or so. The results suggest that there is a strong random component in the river flow process, the changes are weak and the spatial pattern is complex. Yet, the results of trend detection in different indices of river flow in Poland show that there exists a spatial divide that seems to hold quite generally for various indices (annual, seasonal, as well as low and high flow). Decreases of river flow dominate in the northern part of the country and increases usually in the southern part. Stations in the central part show mostly 'no trend' results. However, the spatial gradient is apparent only for the data for the period 1981-2016 rather than for 1956-2016. It seems also that the magnitude of increases of river flow is generally lower than that of decreases.
\end{abstract}

Keywords River flow $\cdot$ Trend detection $\cdot$ High flows $\cdot$ Low flows $\cdot$ Poland

\section{Introduction}

The issue of trend detection in long time series of river flow records is a very important task of vast theoretical interest and considerable practical relevance (Kundzewicz et al. 2005). The former statement reflects the search for impacts of the ongoing climate change. Climate change track is easy to find in records of increasing temperature, but the situation is far more complex in precipitation and even more so in river flow records. The latter statement reflects the fact that water management is based on the assumption

Mikołaj Piniewski

m.piniewski@levis.sggw.pl

1 Department of Hydraulic Engineering, Warsaw University of Life Sciences - SGGW, Warsaw, Poland

2 Potsdam Institute for Climate Impact Research, Potsdam, Germany

3 Institute for Agricultural and Forest Environment, Polish Academy of Sciences, Poznań, Poland of stationarity, that is, constancy of statistical properties of the river flow record. Hence, it is crucial to find whether the statistical properties of the record can be regarded as approximately stationary, recognizing that stationarity is only a convenient idealization (Milly et al. 2008, 2015). For instance, flood risk reduction is based on the concept of design flood, with the probability of exceedance in any one year being, depending on the area, 0.01, 0.05, 0.1, etc. River flow corresponding to a given probability of exceedance is the parameter of importance for people responsible for flood preparedness, both from the viewpoint of general natural disaster risk reduction and climate change adaptation, as flood risk tends to increase in the warming climate, with more room for water vapour is the warmer atmosphere (Hanson et al. 2007).

No research known to the authors convincingly demonstrates a regionally ubiquitous and uniform change in river flow at any larger scale (global, continental, regional, national). There exist several contributing (and partly compensating) factors affecting the river flow process. 
As noted by Kundzewicz and Robson (2004), data are indeed the backbone of change detection in hydrological records; hence, conditions that have to be fulfilled by the data are quite demanding. A series of records should be sufficiently long (in relation to the natural variability of the process) for a change to be detected with adequate reliability. The choice of river gauging stations to be used typically reflects such criteria as the length of the time series of good-quality records as well as the currency of records that should extend through to a recent past. Missing values and gaps in data are complicating factors. It is advantageous to seek a representative geographical coverage, while avoiding the inclusion of many neighbouring (and possibly correlated) gauging stations in the data set. Also, catchment size is of relevance, with priority given to smaller catchments which are more likely to have less strong anthropogenic influence in comparison to larger catchments. Selection of stations to use in a climate change impact study is particularly important (cf. Kundzewicz and Robson 2004). River flow is the integrated result of natural factors, such as precipitation, catchment storage and evaporation, as well as catchment management practices and river engineering that alter the river conveyance system over time. This complicates the problem of detecting a climate change signature in river flow data (Kundzewicz et al. 2005). To assess climatically forced hydrological changes, data should be taken, to the extent possible, from near-pristine drainage basins that are not largely affected by human activities (urbanization, deforestation, reservoirs, drainage systems, water abstraction, river engineering, etc.). Catchments featuring significant changes during the interval of records, related to land use and land cover or river regulation are not appropriate.

The objective of this study is the analysis of long-term trends in selected river flow indices describing annual and seasonal average conditions as well as annual extreme conditions in small- and medium-sized catchments with relatively unmodified flow regime (semi-natural catchments) in Poland. The special focus is on the spatial analysis of trends, carried out on a comprehensive, representative data set of flow gauges used in this study.

Climate change in Poland manifests itself in the most pronounced way in observed temperature records, particularly heat indices (Graczyk et al. 2017). To interpret the change in river flow, it is important to examine the results of change detection studies in precipitation (therein also intense precipitation and snow-related characteristics), where weaker, although apparent trends, were detected, e.g. in precipitation-based drought indices by Somorowska (2016). Pińskwar et al. (2018a) analysed changes in observed daily precipitation records in Poland from 1951 to 2015. Trends were detected, but mostly weak and statistically insignificant. Yet, there are regionally consistent seasonal changes and precipitation increase in spring and winter dominates. Pińskwar et al. (2018b) examined precipitation extremes in Poland, showing that daily maximum precipitation for the summer half-year (Apr.-Sept.) increased for many stations and there were more positive changes during the summer half-year than those in the winter half-year (Oct.-March). The number of days with intense precipitation ( $\geq 10 \mathrm{~mm}$ per day) increased especially in the north-western part of Poland. Szwed et al. (2017) examined the variability of the characteristics of snow cover in Poland. They found that the observed time series of snow-related variables have complex and not easily interpretable behaviour. Yet, a statistical link between the North Atlantic Oscillation (NAO) index and the snow cover depth, as well as the number of snow cover days was found.

Although a substantial amount of studies on trend detection of different types of hydrological indices were published in the Polish language (see, e.g. a review of such studies by Pociask-Karteczka 2011), very few are available for a wider international audience in the English language. Those available ones typically used time series ending in the 1990s (Strupczewski et al. 2001) or early 2000s (Kaczmarek 2003). More recent studies usually focused on single catchments (e.g. Banasik et al. 2013; Ilnicki et al. 2014; Kędra 2017; Miler 2015; Somorowska 2017) or small regions (Niedźwiedź et al. 2015; Ruiz-Villanueva et al. 2016; Sen and Niedzielski 2010), with one notable exception of Wrzesiński and Sobkowiak (2018) who analysed long-term changes (but not trends) in flow regime of 159 flow gauges with a good geographical coverage in Poland. Polish rivers were not included in several pan-European (Hannaford et al. 2013; Stahl et al. 2010) or global (Hodgkins et al. 2017) studies on trend detection, perhaps due to restrictive data sharing policy (Kundzewicz et al. 2017). In summary, a need for a comprehensive trend detection study for Polish river flows is well motivated.

\section{Materials and methods}

\section{River flow data}

Many countries (e.g. Canada, UK, USA) possess networks of gauges with long and uninterrupted river flow records from catchments with minimal anthropogenic activitysometimes referred to as reference hydrometric networks, RHNs (Burn et al. 2012). Such networks are usually subsets of national hydrometric networks and are particularly useful for detecting and attributing trends in river flow indices. Data sets of gauging stations with RHN-like characteristics were also created for large parts of Europe 
(Stahl et al. 2010) or for the Alpine region in central Europe (Bard et al. 2015). Although Poland does not maintain its RHN, in this study we have used a data set of gauging stations with RHN-like features.

In his study of classification of natural flow regimes in Poland, Piniewski (2017) analysed a large observation data set of long time series of river flow records, covering the whole country. Flow data were acquired from the Institute of Meteorology and Water Management, National Research Institute (IMGW-PIB). To select data suitable for this analysis, Piniewski (2017) sought gauging stations in river cross sections terminating small to medium catchments with relatively unmodified flow regime. Selected catchments were characterized by a good geographical coverage taking into account spatial climatic and physiographic variability as well as the length of the available river flow record (Piniewski 2017). Gauges with catchment area of more than $10,000 \mathrm{~km}^{2}$ were excluded, as at this scale flow disturbance is almost unavoidable (Leasure et al. 2016). A comprehensive analysis of available GIS data was carried out to exclude catchments suspected to have a moderate or high degree of flow regime disturbance (cf. Piniewski 2017). For example: (1) all catchments containing reservoirs with capacity above 5 million $\mathrm{m}^{3}$ were excluded; (2) catchments containing cities with population above 200,000 inhabitants were all excluded. Daily hydrographs for all gauges were inspected to identify dubious patterns. It is acknowledged that some, unavoidable, level of human-induced flow alteration is still present in most of the selected catchments; however, some degree of disturbance has to be tolerated (cf. Murphy et al. 2013), and furthermore the work done represented best effort to select the subset of least human-impacted gauges in Poland.

The original set of data consists of 147 stations. In the present study, it was decided to analyse two subsets of the complete data set (Fig. 1). One subset (A) comprised 57 gauges with daily data available for 61 years (1956-2016), while the other subset (B) comprised 144 gauges with daily river flow data available over the time interval of 36 years (1981-2016). Note that data for hydrological years (1 November-31 October) were used here. This decision to divide the original data set into subsets reflects the trade-off of having a set of longer time series for a smaller set of stations or a set of shorter time series for a larger set of stations. The subset (A) was selected to maximize the duration of the time series of records, while the subset (B) was selected to maximize the station count and geographical coverage. Stations with data gaps longer than 1 year were avoided, i.e. the maximum length of data gaps for each station in subsets (A) and (B) was 1 year. As shown in Fig. 1, only four stations in subset (A) and ten stations in subset (B) had 1-year-long data gaps, whereas several further stations had much shorter gaps (mean value 15 days). Data infilling was carried out using a simple interpolation method for short gaps (provided that no larger flood events were noted in the neighbouring stations) or regression from donor catchments for short periods with flood events and for all longer periods. However, since the fraction of missing records in the entire studied data set was very low [0.4\% in subset (A) and $0.3 \%$ in subset (B)], it is believed that the infilling procedure did not have any tangible effect on the analyses.

As shown in Fig. 1, geographical coverage of catchments is good, albeit some regions known for their lower human impact (e.g. NE Poland) have a stronger representation. Table 1 presents the basic properties of the selected catchments. The median of catchment areas is equal to $557 \mathrm{~km}^{2}$. The catchments present large variability in climatic parameters (precipitation and temperature), elevation and land cover. Huge variability is also present for hydrological parameters which demonstrate that the catchments are indeed well representative for Polish conditions.

\section{River flow indices}

The indices describing average annual, average seasonal, as well as characteristics of low and high river flow commonly used in water resources management and engineering are examined here. As this study is supposed to serve as a preliminary one in this subject, simple indices were preferred over the more complex ones. For describing average annual and seasonal conditions, the time series of mean annual (denoted as Q_MEAN) and seasonal (denoted as Q_DJF, Q_MAM, Q_JJA and Q_SON for winter, spring, summer and autumn, respectively) flows were calculated. For extreme low flow conditions, the annual minima of 7 day averaged daily flows (denoted as Q7_MIN) were calculated. Finally, as the index of high extremes, the annual maxima of daily flows (Q_MAX) were used. All indices were calculated in $\mathrm{m}^{3} \mathrm{~s}^{-1}$.

To permit comparisons between catchments and analysis of spatial patterns of trend magnitudes, the annual time series of indices listed in Table 2 were first standardized (i.e. values were subtracted from the mean and divided by the standard deviation).

\section{Trend detection}

As in many other studies on trend detection in river flow indices (Kundzewicz and Robson 2004; Stahl et al. 2010; Burn et al. 2012; Hannaford et al. 2013), in this study we also used the non-parametric rank-based Mann-Kendall (MK) test for monotonic trend (Kendall 1975). The test is applicable for non-normally distributed data and data 


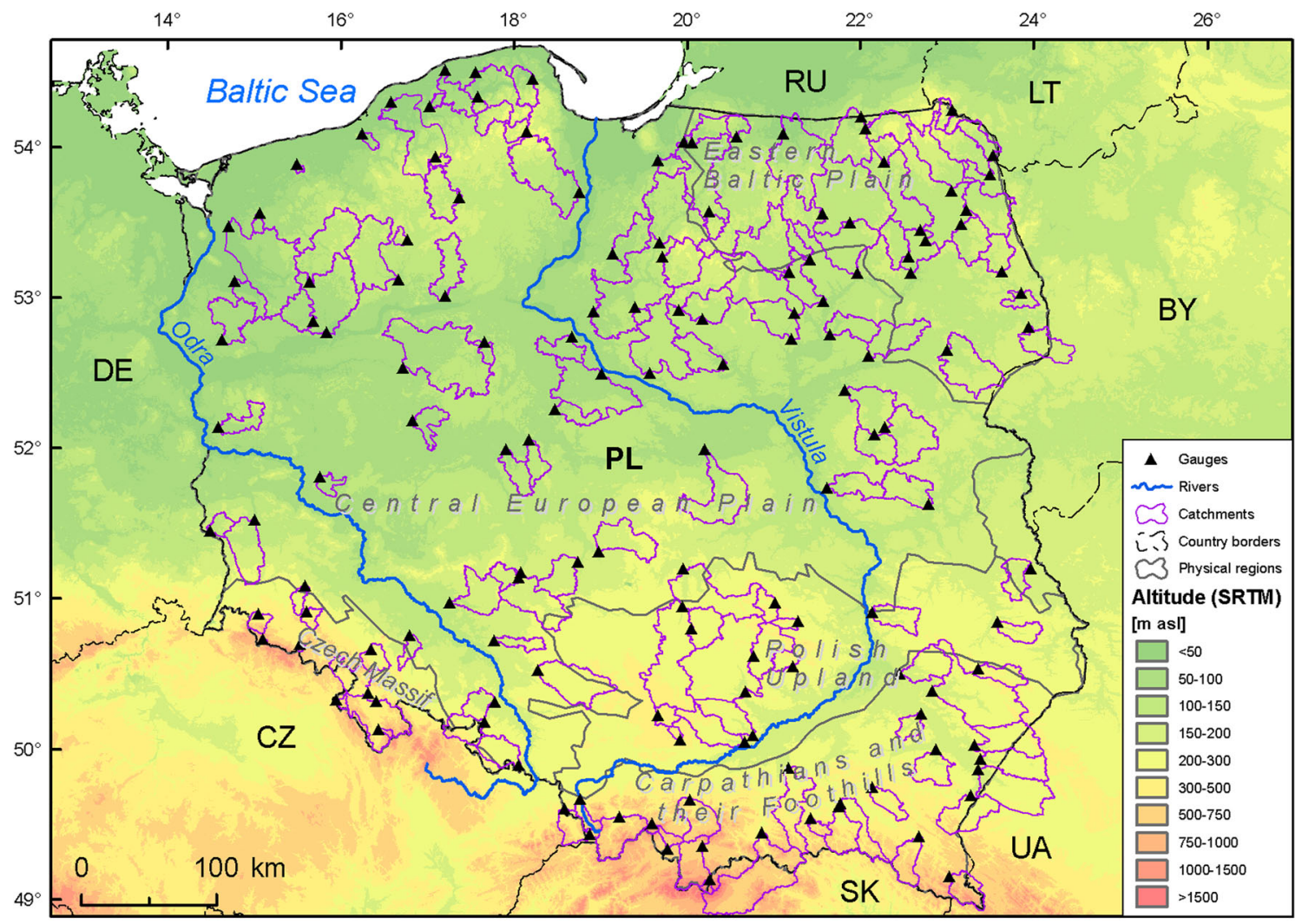

Data availability

Subset A, 57 gauges, 1956-2016

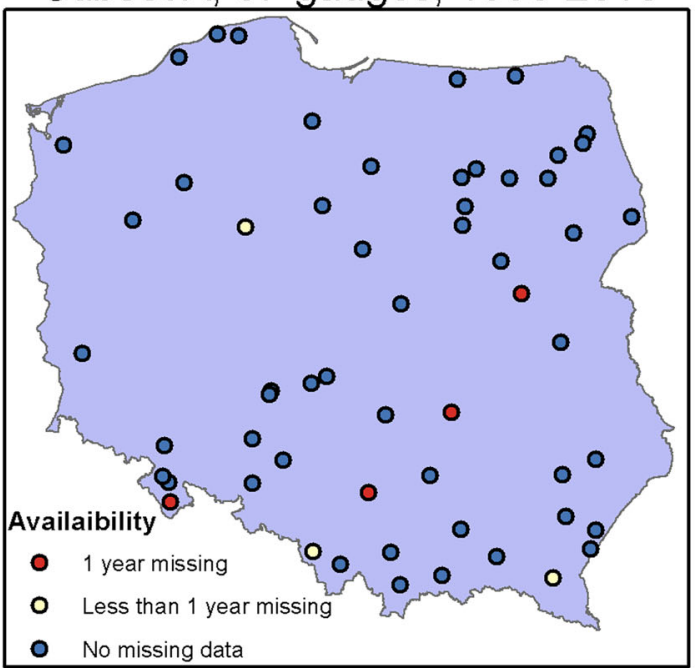

Subset B, 144 gauges, 1981-2016

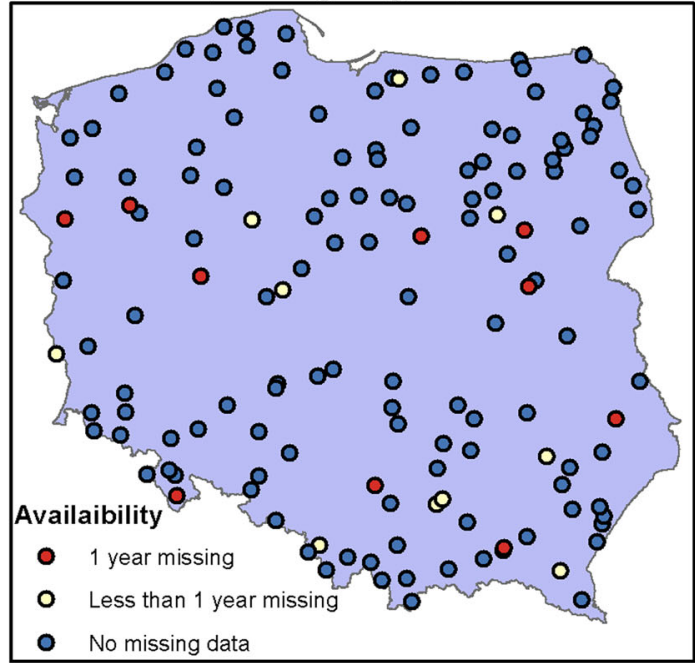

Fig. 1 Gauging stations and catchments used in the present study (adapted from Piniewski 2017) as well as flow data availability for two subsets of gauges within two time periods: 1956-2016 and 1981-2016

containing outliers or non-linear trends (Stahl et al. 2010). The MK statistic, $Z$, is a rank sum standardized by its variance and follows the standard normal distribution with a mean of zero and variance of one. The reader is directed to literature for more details on trend calculation (cf. Kundzewicz and Robson 2004).
Due to controversies around testing statistical significance of changes in river flow indices using the MK test, we have decided to focus on direction and magnitudes of trends and their spatial patterns rather than significance. A frequent presence of auto-correlation in hydrological time series (the Polish ones are no exception here) has a direct 
Table 1 Statistics of selected parameters describing 144 catchments used in this study

\begin{tabular}{|c|c|c|c|c|c|c|c|}
\hline Parameter & Unit & Minimum & 1st quartile & Median & Mean & 3rd quartile & Maximum \\
\hline Catchment area & $\mathrm{km}^{2}$ & 6 & 236 & 557 & 867 & 1034 & 6818 \\
\hline Annual total precipitation & $\mathrm{mm} /$ year & 587 & 660 & 695 & 760 & 781 & 1385 \\
\hline Winter total precipitation & $\mathrm{mm} /$ year & 102 & 128 & 136 & 152 & 170 & 320 \\
\hline Summer total precipitation & $\mathrm{mm} /$ year & 213 & 236 & 248 & 265 & 267 & 456 \\
\hline Annual mean temperature & ${ }^{\circ} \mathrm{C}$ & 0.2 & 7.0 & 7.5 & 7.4 & 7.9 & 8.9 \\
\hline Winter mean temperature & ${ }^{\circ} \mathrm{C}$ & -7.6 & -2.7 & -2.2 & -2.1 & -1.3 & -0.1 \\
\hline Summer mean temperature & ${ }^{\circ} \mathrm{C}$ & 8.1 & 16.4 & 16.9 & 16.6 & 17.3 & 17.9 \\
\hline Mean elevation & $\mathrm{m}$ asl & 54.6 & 130.2 & 170.6 & 263.8 & 283.8 & 1647.2 \\
\hline Percent of forests & $\%$ & 2.5 & 22.0 & 33.1 & 37.2 & 48.9 & 100.0 \\
\hline Percent of agricultural land use & $\%$ & 0.0 & 46.0 & 62.6 & 58.6 & 74.2 & 93.4 \\
\hline Annual mean flow & $\mathrm{m}^{3} / \mathrm{s}$ & 0.3 & 1.4 & 3.0 & 5.4 & 6.8 & 37.0 \\
\hline Coefficient of variation of daily flows & - & 0.25 & 0.65 & 1.02 & 1.06 & 1.36 & 3.37 \\
\hline Mean annual specific runoff & $\mathrm{mm} /$ year & 45 & 128 & 172 & 246 & 266 & 1581 \\
\hline
\end{tabular}

Table 2 List of river flow indices used in this study

\begin{tabular}{lll}
\hline Index & Abbreviation & Category \\
\hline Mean annual flow & Q_MEAN & Average conditions \\
Winter season mean flow & Q_DJF & Seasonal conditions \\
Spring season mean flow & Q_MAM & Seasonal conditions \\
Summer season mean flow & Q_JJA & Seasonal conditions \\
Autumn season mean flow & Q_SON & Seasonal conditions \\
Annual minimum of 7-day mean flows & Q7_MIN & Extreme conditions \\
Annual maximum daily flow & Q_MAX & Extreme conditions \\
\hline
\end{tabular}

effect on MK test significance (Hamed and Rao 1998; Yue and Wang 2002). Streamflow time series are also known to exhibit what is called a long-term persistence (LTP; Cohn and Lins 2005; Koutsoyiannis and Montanari 2007), which violates the assumptions of the MK test. Furthermore, significance levels usually have an arbitrary nature (Hannaford et al. 2013).

Sen slopes (Sen 1968) were calculated for estimation of trend magnitudes for each index and station. They are calculated using a simple, non-parametric, procedure, as the median of slopes of all possible ordered pairs of time series values. Sen slopes are more robust to outliers than parametric tests such as linear regression. Since slopes are calculated based on standardized time series, they are expressed in standard deviations of a given index value per year. It should be also noted that the existence of autocorrelation does not affect the estimated value of the Sen slope, unlike the $p$ value of the MK test (Yue et al. 2002).

\section{Results}

\section{Mean annual flow}

For both studied periods and corresponding station subsets, decreasing trends in mean annual flow are prevailing in observation records in Poland (Fig. 2). An important feature of the larger subset of stations is a clear division of the country into three latitudinal zones: (1) northern part, in which decreasing trends dominate (particularly strong in its central part); (2) central part, in which trends are very weak; (3) southern part, in which Q_MEAN increases for the majority of gauges. In contrast, for the time interval 1956-2016, for approximately half of gauging stations scattered around Poland, no trends were identified.

\section{Mean seasonal flows}

Mean seasonal flows are characterized by fairly similar changes as mean annual flows, i.e. between-season differences are not very large (Fig. 3). Overall, decreasing trends are more common than increasing trends for all seasons. Trend slopes are lower for the smaller subset of stations 
1956-2016, 57 stations

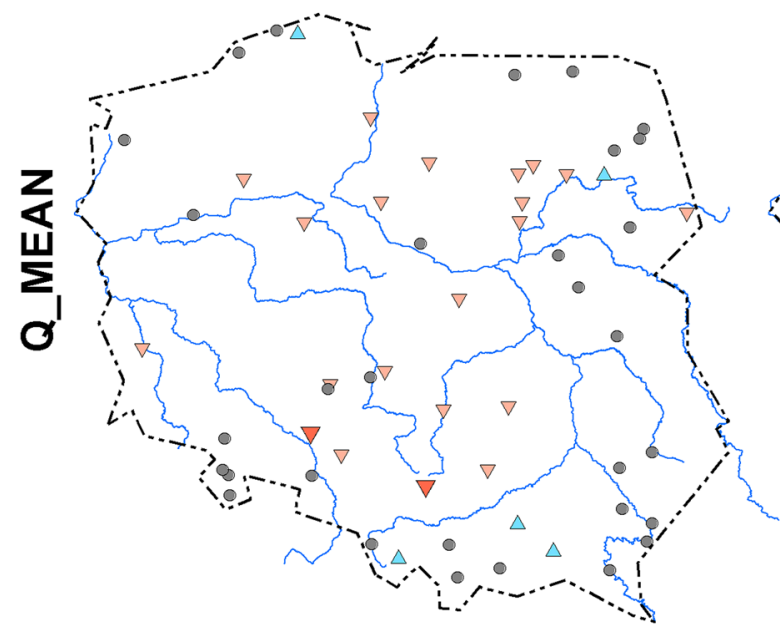

1981-2016, 144 stations

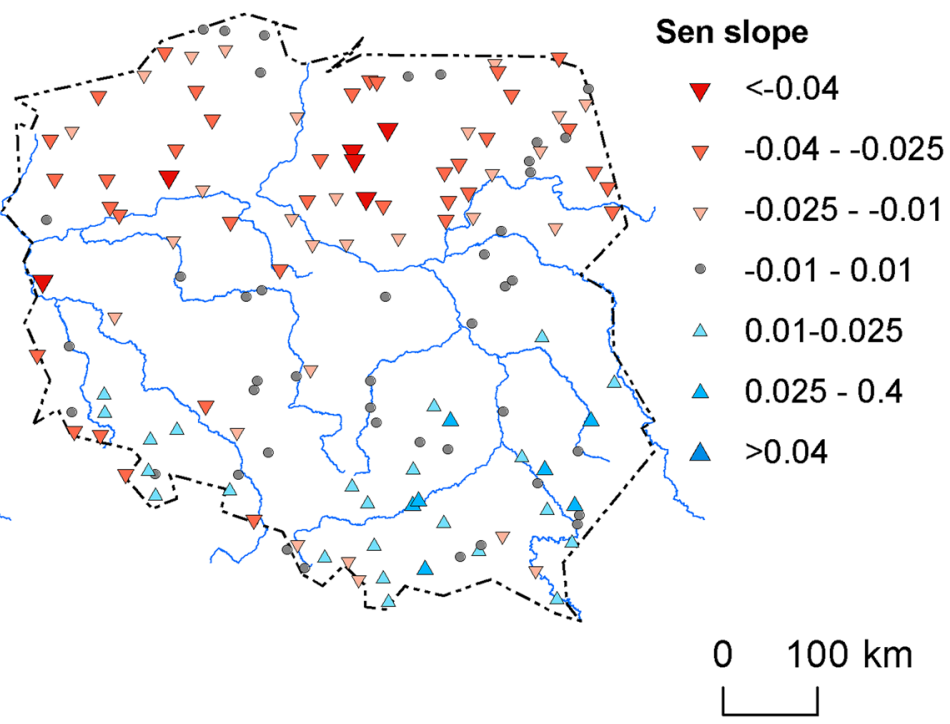

Fig. 2 Trend magnitudes (described by Sen slope) of mean annual flow (Q_MEAN) time series for two time periods: $1956-2016$ [subset (A), 57 flow gauges] and 1981-2016 [subset (B), 144 gauges]

possessing data for a longer period than for the larger subset and shorter period. In the latter case, latitudinal pattern of change can be observed for every season (as for Q_MEAN), with seasonal flow decreases dominating in the northern part, increases prevailing in the southern part, and low trend slopes for stations in the central part of Poland. The highest decreases can be noted for Q_MAM in the northern part of Poland, but only for the subset (B). Since the river flow maxima, typically of snowmelt origin, are usually reached in the spring season in this region of Poland, it is expected that similar decreases will be obtained for Q_MAX.

\section{Low flows and floods}

Figure 4, describing spatial variability of trend slopes in Q7_MIN and Q_MAX, supports previous findings from Figs. 2 and 3 that absolute values of the Sen slope are higher for shorter time intervals. As in the case of mean annual and seasonal flows, decreases in minimum and maximum river flow indices in the time interval 1981-2016 are the highest in the northern part of Poland. The spatial pattern in the southern part of Poland has a more mixed nature, with a considerable number of stations undergoing increases, decreases, or little changes. It is worthy of stating that decreases of Q7_MIN are observed in areas where the mean river flow is low, in general. Hence, the problems related to streamflow drought are likely getting exacerbated.

\section{Summary of trends}

As presented in Table 3, the time period 1981-2016 for which a larger gauging station data set was available is characterized by a higher level of agreement between the studied river flow indices. Only for Q_SON, the autumn season average flow, only $58 \%$ of stations have a negative trend, while for the remaining six indices it ranges between 66 and 68\%. For the longer period 1956-2016, in one case, for Q_DJF, more stations show increasing than decreasing trends. In contrast, in the case of annual maximum flow (Q_MAX), only $21 \%$ of gauges show increasing trends. It should be noted though that trend magnitudes for the longer period were generally lower (Figs. 2, 3, 4).

\section{Inter-annual variability in river flow indices}

In addition to studying trends in river flow indices, it is important to track their inter-annual variability (Fig. 5). Since, as shown in Table 3, for all indices there are stations showing either increasing or decreasing trends, Fig. 5 uses a selection of stations, of which one always shows a negative trend (left column) and the other shows a positive trend (right column). Example flow gauges were selected for each index separately, in such a manner that they represented a region in which most of the stations showed trends in a similar direction. Thus, the majority of stations showing negative trends are located in the northern part of Poland, whereas most of the stations showing positive trends are situated in the southern part. Plotted trend lines 


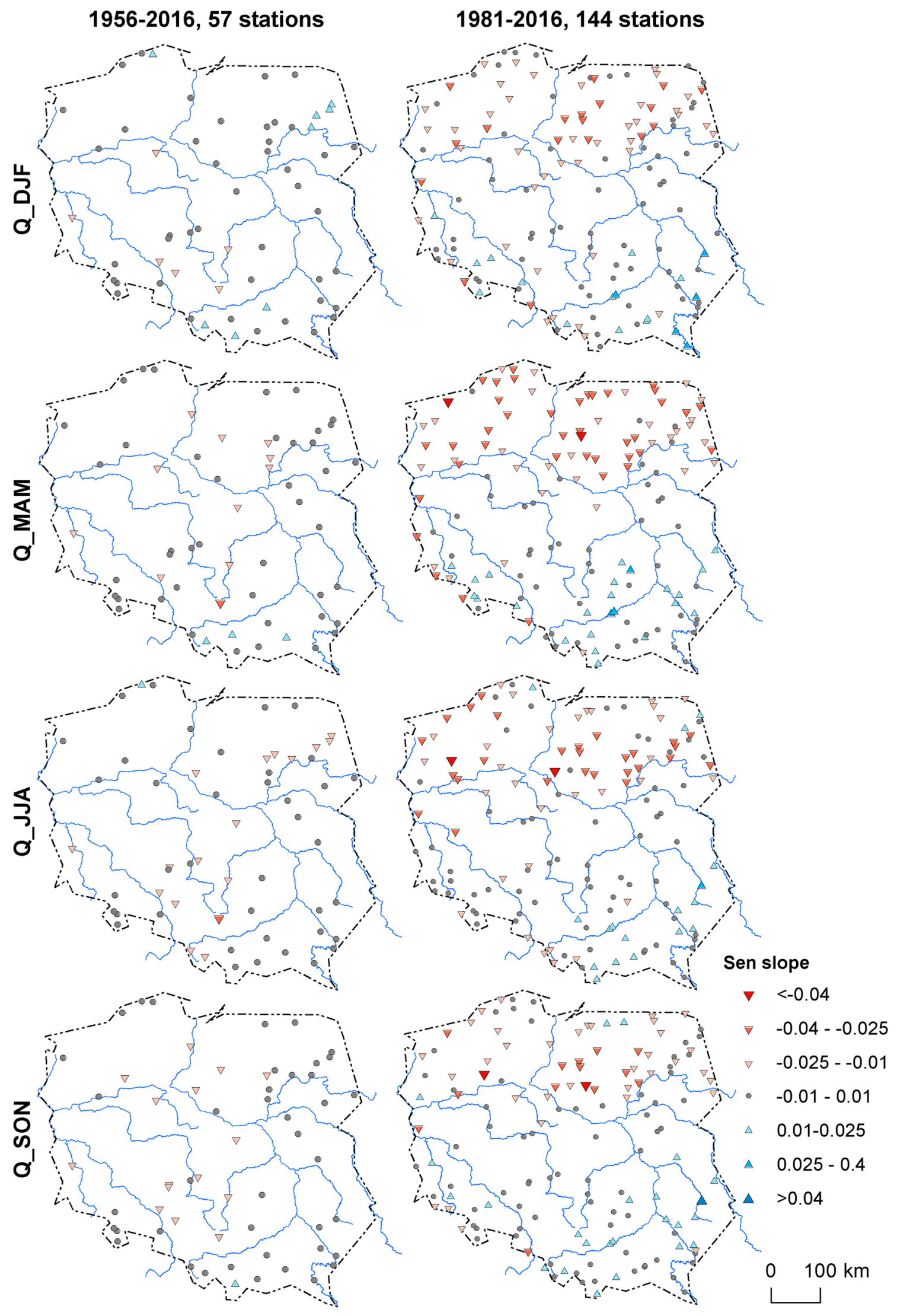


4Fig. 3 Trend magnitudes (described by Sen slope) of mean seasonal flow (winter, spring, summer and autumn, denoted as Q_DJF, Q_MAM, Q_JJA and Q_SON, respectively) time series for two time periods: 1956-2016 [subset (A), 57 flow gauges] and 1981-2016 [subset (B), 144 gauges] using Sen slopes are drawn for the two studied periods: 1956-2016 and 1981-2016, which means that only stations from the less abundant subset (A) of longer duration of record were selected.

Trend slopes for two studied periods can be quite different, as for example in the case of River Orzyc at Maków
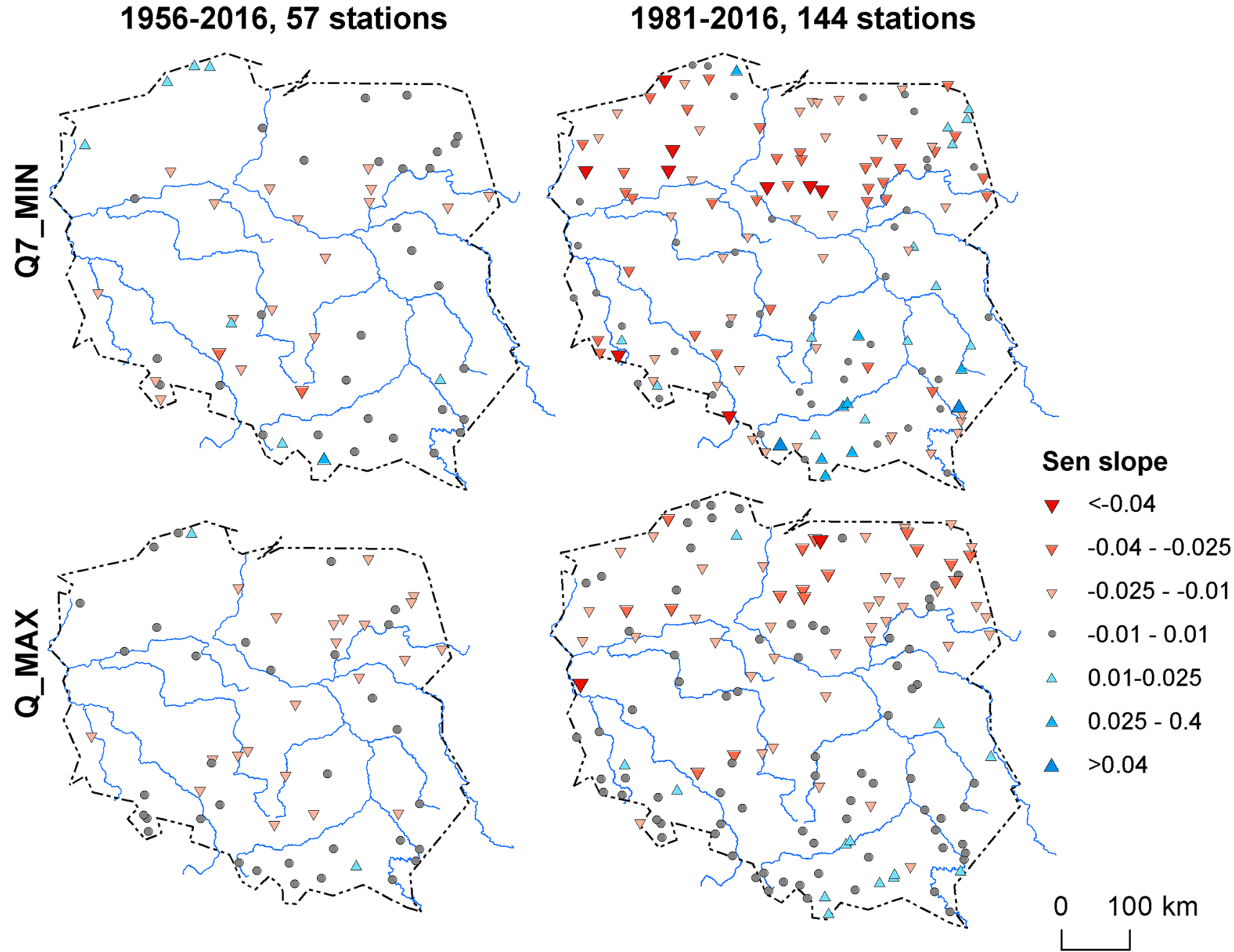

Fig. 4 Trend magnitudes (described by Sen slope) of annual minimum of 7-day average flows (Q7_MIN) and annual maximum flow (Q_MAX) time series for two time periods: 1956-2016 (subset (A), 57 flow gauges) and 1981-2016 (subset B, 144 gauges)

Table 3 Summary of trend directions for different river flow indices and two analysed subsets

\begin{tabular}{llllll}
\hline Index & \multicolumn{2}{l}{$1956-2016(57$ stations $)$} & & \multicolumn{2}{c}{ 1981-2016 (144 stations) } \\
\cline { 2 - 3 } & Increase (\%) & Decrease (\%) & & Increase (\%) & Decrease (\%) \\
\hline Q_MEAN & 26 & 74 & 34 & 66 \\
Q_DJF & 54 & 46 & 33 & 67 \\
Q_MAM & 32 & 68 & 33 & 67 \\
Q_JJA & 25 & 75 & 34 & 66 \\
Q_SON & 26 & 74 & 42 & 58 \\
Q7_MIN & 39 & 61 & 32 & 68 \\
Q_MAX & 21 & 79 & 33 & 67 \\
\hline
\end{tabular}


Fig. 5 Inter-annual dynamics of selected river flow indices (standardized values) in selected catchments. Black dashed and dotted lines denote trends obtained using Sen slope for 1956-2016 and 1981-2016, respectively. For each index, two example gauges are shown. River-gauge codes are: ROZMYS (River Rozoga at Myszyniec), WIS-ZOL (Wisłoka at Żółków), DRWELG (Drwęca at Elgiszewo), BIE-OSO (Biebrza at Osowiec), ORZ-MAK (Orzyc at Maków Mazowieski), PRO-MIR (Prosna at Mirków), POP-STA (Poprad at Stary Sącz), WIEBRO (Wierzyca at Brody), DUN-NOW (Dunajec at Nowy Targ), GRA-GRA (Grabia at Grabno), BRZ-KAR

(Brzozówka at Karpowicze)
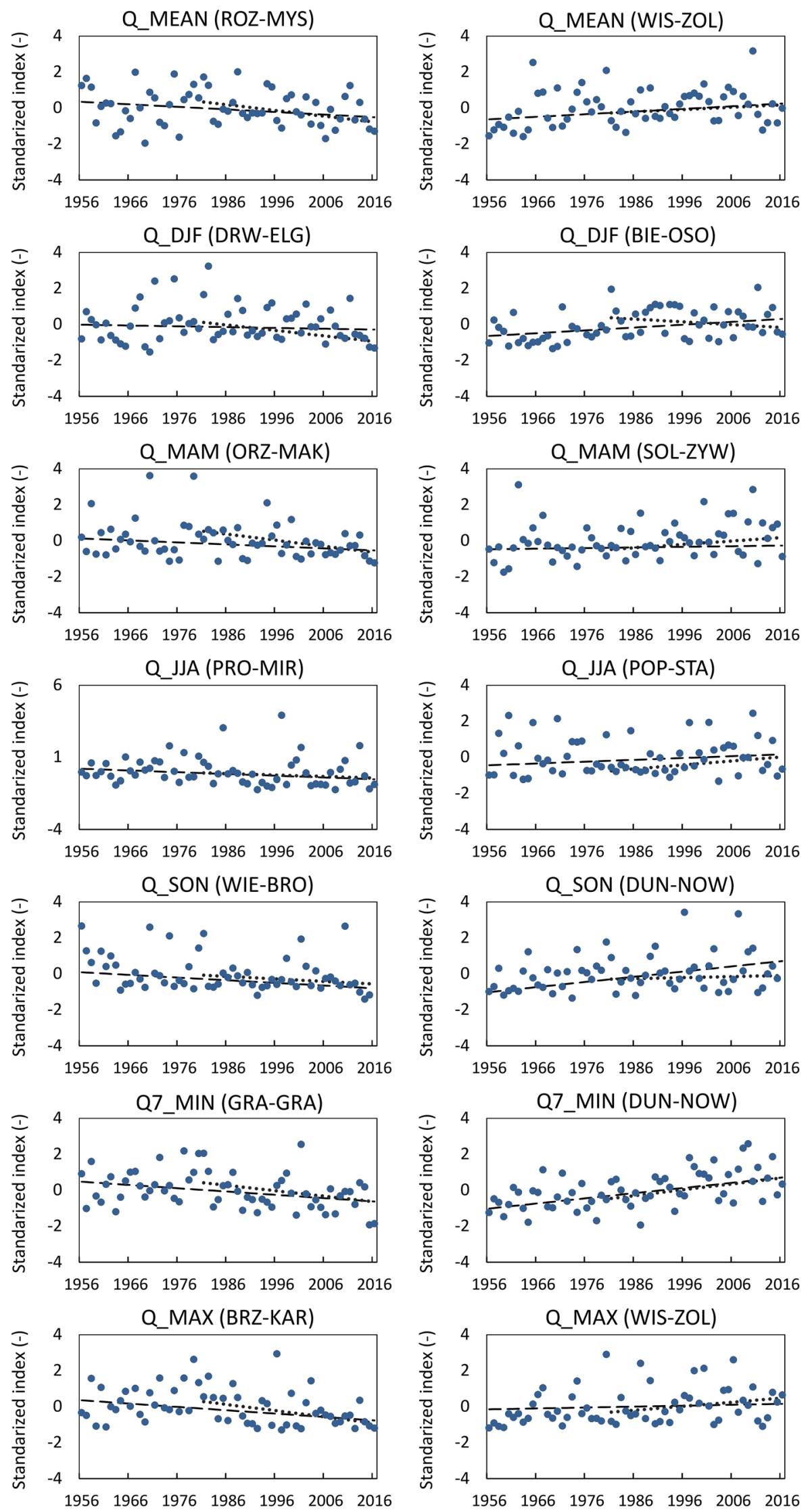
Mazowiecki, for which Q_MAM undergoes a more rapid decrease in the period 1981-2016 than in the period 1956-2016 (Fig. 5). Such a situation is most often the case; however, sometimes the longer period exhibits higher magnitudes of slopes (increases in the River Dunajec at Nowy Targ for Q_SON), and sometimes nearly the same magnitudes are visible for both periods (decreases for the River Prosna at Mirków for Q_JJA).

\section{Relationship between streamflow and catchment characteristics}

Piniewski (2017) calculated a number of climatic, physiographic and hydrological catchment properties for all gauging stations used in this study. We now used the former database of catchment properties to examine possible correlations between them and the trend slopes estimated in the present study. Four example linear regression plots for those combinations of river flow indices and catchment properties that achieved the highest correlations show that, in general, Q_MAM and Q_MEAN had the highest mean correlation across all seven indices (reaching $R^{2}=0.17$ ), whereas the lowest correlation was obtained for Q7_MIN (equal to 0.05) (Fig. 6).

Comparison of calculated $R^{2}$ values across all seven river flow indices suggests that some of the catchment properties had much higher correlation with river flow indices than others. The strongest predictor of Sen slope was the parameter called LOC_DistCoast, denoting distance from the geographical centre of the catchment from the (Baltic Sea) coast. This is in line with Figs. 2, 3 and 4, demonstrating a clear divide of the country into two or three zones, depending on the latitude and distance from the coast. The lower the distance from the coast, the more pronounced is the decrease in river flow indices, for example in Q_MAM for which the correlation was the highest (Fig. 6). The ratio of outwash sands and gravels (GEO_outsand) was another good predictor of trend slope magnitude, with catchments rich in this type of bedrock having generally more pronounced decreasing trends, particularly in Q_SON. A similar relationship was present between the ratio of lakes (HYD_Lake) and Q_DJF (but not other indices). Finally, the coefficient of variation of daily flows (Q_CV) was positively correlated with the Sen slope magnitude for several indicators, in particular with Q_MEAN as shown in Fig. 6. It is also noteworthy that other possibly important catchment properties such as drainage area or some temperature and precipitation indices had lower correlation values than those shown in Fig. 6.

\section{Discussion}

In the light of the objective of this study mentioned in "Introduction", the special focus was on the spatial analysis of trends, carried out on a comprehensive, representative data set of river flow used in this study. This paper addresses a visible need for a comprehensive trend detection study for Polish river flows.

The results of trend detection in different indices of river flow in Poland presented in this paper show that there exists a spatial divide that seems to hold quite generally for various indices that were examined. Decreases of river flow were found to dominate in the northern part, while increases dominate in the southern part. The central part, extending around a central parallel over Poland, being a transition zone between the north and the south, is frequently characterized by the majority of 'no trend' results. It should be noted, though, that this spatial gradient is apparent only for the results based on the larger subset of stations having data available for the period 1981-2016, and not really for the longer period 1956-2016, with a lower number of stations. This is in accordance with the study of Ilnicki et al. (2014) which observed that trends in mean annual discharge of the River Warta were going in opposite directions (positive in 1950-1980 and negative in 1981-2010). Furthermore, the magnitude of increases is generally lower than that of decreases. The results also show that one of the indicators of geographical location, distance of catchment centroid from the coast, is a very good predictor of trend slopes for all but one index. The highest correlation occurred between the location from the coast and the spring season average flow. This finding is quite similar to the one reported by Kriaučiūnienè et al. (2012), who mentioned that moderate decreases in spring flows can be noted in the western, maritime regions of the Baltic States, while they are absent in eastern, continental regions. In the Polish case, the distance from the coast is on one hand correlated with climatic indices (maritime vs. continental climate), but also with some of the physiographic catchment properties, which is connected to the glacial legacy of Polish landscape. The surface slope basically declines northwards (with some exceptions), but geomorphic properties, e.g. the type of prevailing postglacial deposits on the vast Polish plain, also exhibit clear spatial trends.

Dominating downward trends in river flow indices detected in this study for rivers situated on the Polish plain are supported by publications of other authors (Banasik et al. 2013; Somorowska 2017). Upward trends in mean winter and spring season flows found in this study for numerous stations located in the southern part of Poland were also found by Kędra (2017) for the River Soła located 

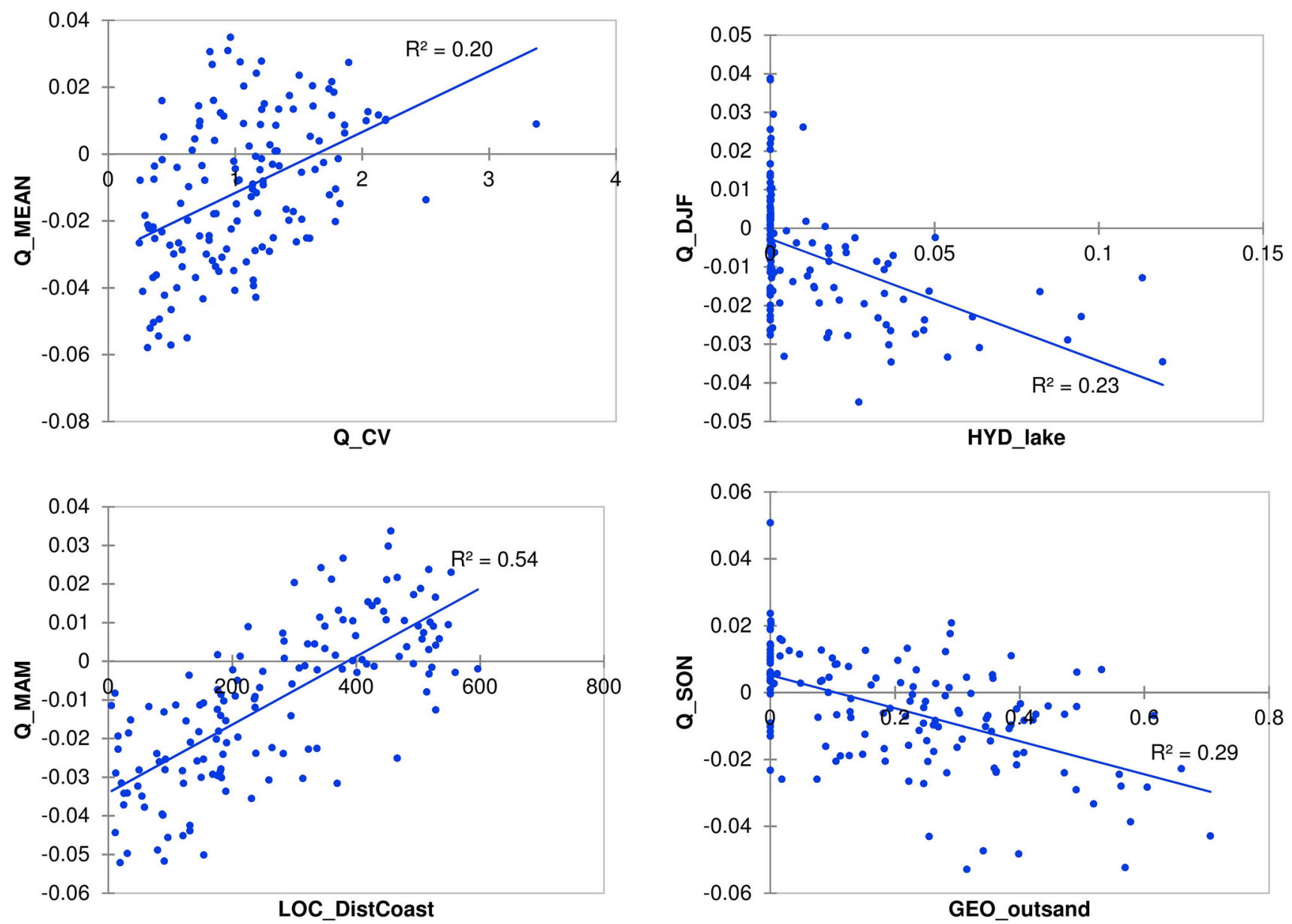

Fig. 6 Linear regression between Sen slopes for selected river flow indices (Q_MEAN, Q_DJF, Q_MAM and Q_SON) for subset (B) (144 stations) and selected catchment properties $\left(Q_{-} C V\right.$ coefficient of variation of daily flows, HYD_lake ratio of lakes,

in the Carpathians. The results of a multi-temporal trend analysis performed for annual maximum flows by RuizVillanueva et al. (2016) for rivers in the Dunajec catchment demonstrated that trend direction depends on the analysis period. While increasing trends were prevailing for periods starting in the 1960s and ending in the 1990s, the opposite direction of trends was noted for later periods, i.e. starting in the 1980s and ending in the 2000s. Kaczmarek (2003) reported decreasing trends in snowmelt-induced floods in four major Polish rivers: Vistula, Odra, Warta and Bug, which partly corroborates our findings on decreases in Q_MAX and Q_MAM, especially in northern Poland. Pociask-Karteczka (2011) analysed trends in mean annual flows of the Vistula and Odra rivers concluding that "statistically significant increase or decrease in river discharge in Poland as a response to climate changes in Poland has not been observed". Our study shows that in Polish rivers whose drainage areas are two to five orders of magnitude
LOC_DistCoast distance from coast, GEO_outsand ratio of outwash sands and gravels). See Piniewski (2017) for more details on calculated catchment properties

lower than those of the Vistula and Odra $\left(10^{0}-10^{3}\right.$ vs. $10^{5}$ $\mathrm{km}^{2}$ ), certain trends can be detected, although the picture is rather complex. Stonevicius et al. (2014) detected strong upward trends in winter flows in Lithuanian rivers. This result is different from the one obtained in the present study for rivers situated in NE Poland, in close proximity to the Lithuanian border. Bormann and Pinter (2017) evaluated trends in low flows in Germany, presenting maps illustrating strong upward trends in southern and central Germany, and non-significant or downward trends in its northern part. The pattern observed for Polish rivers in this study was quite similar. It should be noted though that rivers in the study of Bormann and Pinter (2017) were influenced by water management, which can perturb natural climate-driven trends for near-pristine drainage basins, as demonstrated in a study of Marcinkowski and Grygoruk (2017). Wrzesiński and Sobkowiak (2018) demonstrated that the largest changes in the flow regime of Polish rivers 
in the time interval 1951-2010 took place in catchments with the strongest human influence, which partly explains rather weak and unequivocal trends detected in this study for semi-natural catchments.

No research known to the authors convincingly demonstrates a regionally ubiquitous and uniform change in river flow at any larger scale (global, continental, regional, national). Gerten et al. (2012) identified statistically significant changes in average annual discharge across Europe between 1901-1970 and 1971-2002 and proposed attribution of changes. However, the resultant map of changes is complex and heterogeneous. Over Poland, their results differ from those presented in the present study and this is understandable for several reasons (selection of different time horizons of analysis, use of model-based simulations over all grids in contrast to raw observation data on catchments in Poland that were found not to be heavily modified).

To interpret the change in river flow it is important to examine the results of change detection studies in precipitation (therein also intense precipitation) and snow cover. However, even if trends were detected, they were mostly weak and statistically insignificant. Yet, there are regionally consistent seasonal changes and precipitation increase in spring and winter dominates. Pińskwar et al. (2018b) showed that daily maximum precipitation for the summer half-year (Apr.-Sept.) increased for many stations and there were more positive changes during the summer halfyear than those in the winter half-year (Oct.-March). Szwed et al. (2017) found that observed tendencies in time series of snow-related variables is complex and not easy to interpret. Yet, statistical relations between the North Atlantic Oscillation (NAO) index and the snow cover depth, as well as the number of snow cover days were found. Quasi-cyclic variability in some of the river flow indices can also be noted in Fig. 6; however, investigation of correlation between NAO (or similar indices) and trend results presented herein was beyond the scope of this study. We refer the reader to other studies devoted to this phenomenon, e.g. Rutkowska et al. (2017), Pociask-Karteczka (2006), Wrzesiński (2011) and a recent review article of Steirou et al. (2017).

Comparison of results of trend detection with river flow projections shows that projections build a far more spatially homogeneous map than the observation records and this is not surprising. By construction, projections (cf. Piniewski et al. 2017b, c) are based on smooth information from climate models (subject to empirical-statistical or dynamical downscaling and bias correction). Moreover, projections show likely increases of mean annual and seasonal flows (cf. Piniewski et al. 2017b) as well as indices of low and high flows (cf. Piniewski et al. 2017c), which are driven by projected increases in precipitation, particularly in winter and spring seasons (Piniewski et al., 2017a). Hence, there are many places in Poland where the direction of change of river flow does not correspond between observations and projections, rendering interpretation a considerable conceptual dilemma. Although much effort has been undertaken to select flow gauges free of visible human pressure, there is a risk that at least for some of the catchments other effects could play their role.

It is important to stress that time series of annual maximum and annual minimum (7-day) flows, analysed in this study, convey information on some river discharge extremes only. This broadly used approach is straightforward and well established. However, in years with more than one high-flow episode, only one flood event per year is selected, while in years with no large flows at all, a nonflood (medium or even low) flow, in absolute terms, could have been extracted as the annual maximum. An alternative is a peak-over-threshold (POT) approach, where all independent floods above a certain threshold (i.e. possibly several events in one year and none in another year) are considered (Kundzewicz et al. 2005). Likewise, in generally wet years, the annual minimum does not have to be a low flow in absolute terms.

\section{Conclusion}

This study analysed long-term trends in selected river flow indices over two time intervals (1956-2016 and 1981-2016) in small- and medium-sized catchments with relatively unmodified flow regime (semi-natural catchments) in Poland. The examined indices describe annual and seasonal average conditions as well as annual extreme conditions-low and high flows. Geographical coverage of catchments in this study is good, albeit some regions known for their lower human impact (e.g. NE Poland) have a stronger representation. Two selected time windows demonstrate the sensitivity of the river flow process to the selection of the study period. The more recent period, however, is of more practical interest for water managers.

Altogether, there is a strong random component in the river flow process, the changes are weak and the spatial pattern is complex. For both studied periods and for two station subsets (providing longer time series at fewer stations or shorter time series at more stations), decreasing trends in mean annual flow are prevailing in observation records in Poland. Yet, the results of trend detection in different indices of river flow in Poland show, for 1981-2016, the existence of a spatial divide that seems to hold quite generally for various indices (annual, seasonal, as well as low and high flow). Decreases of river flow dominate in the northern part of the country, while increases usually dominate in the southern part. At stations 
in the central part changes are mostly very weak. It seems that the magnitude of increases of river flow is generally lower than that of decreases. In contrast, for the time interval 1956-2016, for approximately half of gauging stations scattered around Poland, no trends were identified. It is worthy of stating that decreases of low flow are observed in areas where the mean river flow is low, in general. Hence, the problems related to streamflow drought have likely been exacerbated.

It was found that some catchment properties have a fairly strong correlation with river flow indices. The strongest predictor of the Sen slope was the distance from the geographical centre of the catchment from the Baltic Sea coast. In this context, one can interpret the existence of a clear divide of the country into two or three zones, depending on the latitude and distance from the coast.

Trend detection in long time series of river flow records is an activity of vast theoretical interest and considerable practical relevance. The former statement reflects the search for impacts of the ongoing climate change and for adaptation needs. Climate change track is easy to find in records of overwhelmingly increasing temperature, but the situation is far more complex for precipitation and even more so for river flow records, where several contributing (and partly compensating) factors play a role. The latter statement reflects the fact that water management is based on the assumption of stationarity, that is, constancy of statistical properties of the river flow record. Hence, it is crucial to check, on a regular basis and using updated records, whether taking this assumption is justified, i.e. whether the statistical properties of the record can be regarded as approximately stationary. For instance, flood risk reduction is based on the concept of design flood; hence, river flow corresponding to a given probability of exceedance is the parameter of importance for people responsible for flood preparedness, both from the viewpoint of general natural disaster risk reduction and climate change adaptation, as flood hazard is expected to increase in the warming climate, with more room for water vapour in the warmer atmosphere.

Acknowledgements The support of the projects CHASE-PL (Climate Change Impact Assessment for Selected Sectors in Poland) of the Polish-Norwegian Research Programme operated by the National Centre for Research and Development (NCBiR) under the Norwegian Financial Mechanism 2009-2014 in the frame of Project Contracts No. Pol Nor/200799/90/2014 is gratefully acknowledged. The first author thanks the Alexander von Humboldt Foundation and the Ministry of Science and Higher Education for the financial support. The Institute of Meteorology and Water Management, National Research Institute (IMGW-PIB) is kindly acknowledged for providing the hydrometeorological data used in this work. All authors are thankful to the two anonymous referees who provided a number of insightful comments that helped to improve the manuscript.

\section{Compliance with ethical standards}

Conflict of interest On behalf of all authors, the corresponding author states that there is no conflict of interest.

Open Access This article is distributed under the terms of the Creative Commons Attribution 4.0 International License (http://creative commons.org/licenses/by/4.0/), which permits unrestricted use, distribution, and reproduction in any medium, provided you give appropriate credit to the original author(s) and the source, provide a link to the Creative Commons license, and indicate if changes were made.

\section{References}

Banasik K, Hejduk L, Hejduk A, Kaznowska E, Banasik J, Byczkowski A (2013) Long-term variability of runoff from a small catchment in the region of the Kozienice Forest. Sylwan 158:578-586

Bard A, Renard B, Lang M, Giuntoli I, Korck J, Kobolsching G, Janza M, d'Amico M, Volken D (2015) Trends in the hydrologic regime of Alpine rivers. J Hydrol 529:1823-1837

Bormann H, Pinter N (2017) Trends in low flows of German rivers since 1950: comparability of different low-flow indicators and their spatial patterns. River Res Appl 33:1191-1204

Burn DH, Hannaford J, Hodgkins GA, Whitfield PH, Thorne R, Marsh T (2012) Reference hydrologic networks II. Using reference hydrologic networks to assess climate-driven changes in streamflow. Hydrol Sci J 57(8):1580-1593

Cohn TA, Lins HF (2005) Nature's style: naturally trendy. Geophys Res Lett 32(23):L23402

Gerten D, Lucht W, Kundzewicz ZW (2012) Detection and attribution of changes in water resources. In: Kundzewicz ZW (ed) Changes in flood risk in Europe, Special Publication No. 10. IAHS Press, Wallingford, pp 422-434

Graczyk D, Pińskwar I, Kundzewicz ZW, Hov Ø, Førland EJ, Szwed M, Choryński A (2017) The heat goes on-changes in indices of hot extremes in Poland. Theor Appl Climatol 129(1-2):459-471

Hamed KH, Rao AR (1998) A modified Mann-Kendall trend test for autocorrelated data. J Hydrol 204:182-196

Hannaford J, Buys G, Stahl K, Tallaksen LM (2013) The influence of decadal-scale variability on trends in long European streamflow records. Hydrol Earth Syst Sci 17:2717-2733

Hanson CE, Palutikof JP, Livermore MTJ, Barring L, Bindi M, CorteReal J, Durao R, Giannakopoulos C, Good P, Holt T, Kundzewicz ZW, Leckebusch GC, Moriondo M, Radziejewski M, Santos J, Schlyter P, Schwarb M, Stjernquist I, Ulbrich U (2007) Modelling the impact of climate extremes: an overview of the MICE project. Clim Change 81:163-177. https://doi.org/ 10.1007/s10584-006-9230-3

Hodgkins GA, Whitfield PH, Burn DH, Hannaford J, Renard B, Stahl K, Fleig AK, Madsen H, Mediero L, Karhonen J, Murphy C, Wilson D (2017) Climate-driven variability in the occurrence of major floods across North America and Europe. J Hydrol 552:704-717

Ilnicki P, Farat R, Górecki K, Lewandowski P (2014) Impact of climatic change on river discharge in the driest region of Poland. Hydrol Sci J 59(6):1117-1134

Kaczmarek Z (2003) The impact of climate variability on flood risk in Poland. Risk Anal 23:559-566

Kędra M (2017) Long-term trends in river flow: a case study of the Soła River (Polish Carpathians). In: E3S Web of Conferences, vol 19. https://doi.org/10.1051/e3sconf/20171902012

Kendall MG (1975) Rank correlation methods. Griffin, London 
Koutsoyiannis D, Montanari A (2007) Statistical analysis of hydroclimatic time series: uncertainty and insights. Water Resour Manag 43:W05429. https://doi.org/10.1029/2006WR005592

Kriaučiūnienè J, Meilutytė-Barauskiene D, Reihan A, Koltsova T, Lizuma L, Šarauskienè D (2012) Variability in temperature, precipitation and river discharge in Baltic States. Boreal Environ Res 17:150-162

Kundzewicz ZW, Robson AJ (2004) Change detection in river flow records-review of methodology. Hydrol Sci J 49(1):7-19

Kundzewicz ZW, Graczyk D, Maurer T, Pińskwar I, Radziejewski M, Svensson C, Szwed M (2005) Trend detection in river flow series: 1. Annual maximum flow. Hydrol Sci J 50(5):797-810

Kundzewicz ZW, Førland EJ, Piniewski M (2017) Challenges for developing national climate services-Poland and Norway. Clim Serv 8:17-25

Leasure DR, Magoulick DD, Longing SD (2016) Natural flow regimes of the Ozark-Ouachita interior highlands region. River Res Appl 32:18-35

Marcinkowski P, Grygoruk M (2017) Grygoruk M (2017) Long-term downstream effects of a dam on a lowland river flow regime: case study of the Upper Narew. Water 9:783

Miler AT (2015) Variability of the Warta River water discharge in the city of Poznań as influenced by the Jeziorsko reservoir. Arch Environ Prot 41(3):53-59

Milly PCD, Betancourt J, Falkenmark M, Hirsch RM, Kundzewicz ZW, Lettenmaier DP, Stouffer RJ (2008) Stationarity is dead: whither water management? Science 319:573-574

Milly PCD, Betancourt J, Falkenmark M, Hirsch RM, Kundzewicz ZW, Lettenmaier DP, Stouffer RJ, Dettinger MD, Krysanova V (2015) On critiques of "Stationarity is dead: whither water management?". Water Resour Res 51(9):7785-7789

Murphy C, Harrigan S, Hall J, Wilby RL (2013) Climate-driven trends in mean and high flows from a network of reference stations in Ireland. Hydrol Sci J 58(4):755-772

Niedźwiedź T, Łupikasza E, Pińskwar I, Kundzewicz ZW, Stoffel M, Małarzewski $€$ (2015) Variability of high rainfalls and related synoptic situations causing heavy floods at the northern foothills of the Tatra Mountains. Theor Appl Climatol 119(1-2):273-284

Piniewski M (2017) Classification of natural flow regimes in Poland. River Res Appl 33:1205-1218. https://doi.org/10.1002/rra.3153

Piniewski M, Mezghani A, Szcześniak M, Kundzewicz ZW (2017a) Regional projections of temperature and precipitation changes. Robustness and uncertainty aspects. Met Zeit 26(2):223-234

Piniewski M, Szcześniak M, Huang S, Kundzewicz ZW (2017b) Projections of runoff in the Vistula and the Odra river basins with the help of the SWAT model. Hydrol Res. https://doi.org/ 10.2166/nh.2017.280

Piniewski M, Szcześniak M, Kundzewicz ZW, Mezghani A, Hov $\varnothing$ (2017c) Changes in low and high flows in the Vistula and the Odra basins: model projections in the European-scale context. Hydrol Process 31(12):2210-2225

Pińskwar I, Choryński A, Graczyk D, Kundzewicz ZW (2018a) Observed changes in precipitation in Poland. Geografie (in review)

Pińskwar I, Choryński A, Graczyk D, Kundzewicz ZW (2018b) Observed changes in extreme precipitation in Poland:
1991-2015 versus 1961-1990. Theor Appl Climatol. https:// doi.org/10.1007/s00704-018-2372-1

Pociask-Karteczka J (2006) River hydrology and the North Atlantic Oscillation: a general review. Ambio 35(6):312-314

Pociask-Karteczka J (2011) River runoff response to climate changes in Poland (East-Central Europe). IAHS Publication No. 344, pp $182-187$

Ruiz-Villanueva V, Stoffel M, Wyżga B, Kundzewicz ZW, Czajka B, Niedźwiedź $T$ (2016) Decadal variability of floods in the Northern foreland of the Tatra Mountains Reg. Environ Change 3:603-615

Rutkowska A, Willems P, Onyutha C, Młocek W (2017) Temporal and spatial variability of extreme river flow quantiles in the Upper Vistula River basin, Poland. Hydrol Process 31:1510-1526

Sen PK (1968) Estimates of the regression coefficient based on Kendall's tau. J Am Stat Assoc 63(324):1379-1389. https://doi. org/10.2307/2285891

Sen AK, Niedzielski T (2010) Statistical characteristics of riverflow variability in the Odra River Basin, Southwestern Poland. Pol J Environ Stud 19(2):387-397

Somorowska U (2016) Changes in drought conditions in Poland over the past 60 years evaluated by the Standardized PrecipitationEvapotranspiration Index. Acta Geophys 64(6):2530-2549

Somorowska U (2017) Climate-driven changes to streamflow patterns in a groundwater-dominated catchment. Acta Geophys 65:789-798

Stahl K, Hisdal H, Hannaford J, Tallaksen LM, van Lanen AJ, Sauquet E, Demuth S, Fendekova M, Jodar J (2010) Streamflow trends in Europe: evidence from a dataset of near-natural catchments. Hydrol Earth Syst Sci 14:2367-2382

Steirou LG, Gerlitz L, Apel H, Merz B (2017) Links between largescale circulation patterns and streamflow in Central Europe: a review. J Hydrol 549:484-500

Stonevicius E, Valiuškevicius G, Rimkus E E, Kazys J (2014) Climate induced changes of Lithuanian rivers runoff in 1960-2009. Water Resour 41:592-603

Strupczewski WG, Singh VP, Mitosek HT (2001) Non-stationary approach to at-site flood-frequency modelling. Part III. Flood analysis of Polish rivers. J Hydrol 248:152-167

Szwed M, Pińskwar I, Kundzewicz ZW, Graczyk D, Mezghani A (2017) Changes of snow cover in Poland. Acta Geophys 65:65-76. https://doi.org/10.1007/s11600-017-0007-z

Wrzesiński D (2011) Regional differences in the influence of the North Atlantic Oscillation on seasonal river runoff in Poland. Quaest Geogr 30(3):127-136

Wrzesiński D, Sobkowiak L (2018) Detection of changes in flow regime of rivers in Poland. J Hydrol Hydromech 66(1):55-64

Yue S, Wang C (2002) The Mann-Kendall test modified by effective sample size to detect trend in serially correlated hydrological series. Water Resour Manag 18:201-218

Yue S, Pilon P, Phinney B, Cavadias G (2002) The influence of autocorrelation on the ability to detect trend in hydrological series. Hydrol Process 16:1807-1829 